\title{
The Preparation of Au NPs/RGO-MoO 2 Composite Modified Electrode and Simultaneous Detection of Acetaminophen and Dopamine
}

\section{Jiang-dong Gu}

Shaanxi University of Science and Technology

Qiu-feng An ( $\nabla$ anqf@sust.edu.cn )

Shaanxi University of Science and Technology

\section{Wu Yang}

Northwest Normal University

Ling-yan Pang

Shaanxi University of Science and Technology

\section{Ya-fei He}

Shaanxi University of Science and Technology

\section{Research Article}

Keywords: Acetaminophen, Dopamine, Au NPs, RGO-MoO2, Electrochemical Sensor

Posted Date: September 13th, 2021

DOI: https://doi.org/10.21203/rs.3.rs-861280/v1

License: (c) (1) This work is licensed under a Creative Commons Attribution 4.0 International License. Read Full License 


\title{
The Preparation of $\mathrm{Au}$ NPs/RGO- $\mathrm{MoO}_{2}$ Composite Modified
}

\section{Electrode and Simultaneous Detection of Acetaminophen and}

\author{
Dopamine \\ GU Jiang-dong ${ }^{1}$, An Qiu-feng ${ }^{1}$, Yang Wu ${ }^{2}$, Pang Ling-yan ${ }^{1}$, He Ya-fei ${ }^{3}$ \\ (1. College of Chemistry \& Chemical Engineering,Shanxi University of Science \&Technology, Xi' an 710021, \\ China; 2. College of Chemistry and Chemical Engineering, Northwest Normal University, Lanzhou 730070; 3. \\ Department of Foundation Courses, Tianjin College, Beijing University of Science and Technology, Tianjin \\ 301830, China)
}

Abstract: Dopamine (DA) exists in human body fluids and is the most basic metabolite
of the human body, and it is an important neurotransmitter in the central nervous system
of animals. Acetaminophen (AMP) is commonly used as cold medicine to treat fever
and relieve pain. The safe dosage is very important to human health. Therefore, it is
very important to construct an accurate, efficient and fast detection method for detecting
$\mathrm{AMP}$ and DA. In this paper, $\mathrm{Au} \mathrm{NPs} / \mathrm{RGO}-\mathrm{MoO}_{2}$ composite modified electrode was
prepared for the detection of AMP and DA, We can see that the synergy between $\mathrm{RGO}-$
$\mathrm{MoO}_{2}$ nanomaterials and Au NPs and can promote the electrochemical reaction of
$\mathrm{AMP}$ and DA, and the oxidation peak potential difference is greater than $180 \mathrm{mV}$. The
linear range of the sensor for detecting AMP is $0.05 \sim 320 \mu$ mol/L while the linear range
of DA is $0.6 \sim 260 \mu$ mol/L, and the detection limits are 7.2 nmol/L and 13 nmol/L $(\mathrm{S} / \mathrm{N}=3$ )
respectively. The Au NPs/RGO-MoO $/ \mathrm{GCE}$ sensor can be used for the detection of
AMP and DA in actual samples because of its excellent characteristics such as wide
linear range, lower detection limit, excellent reproducibility, stability, and high
selectivity

Keywords: Acetaminophen, Dopamine, Au NPs, RGO-MoO2, Electrochemical Sensor

Acetaminophen( also called Tylenol and Paracetamol) is used as a medicine to treat colds and also has a good effect on postoperative discomfort(such as pain, skin itching, backache, and fever)of the patients, It can effectively fight bacteria and viruses and is safe for human baby when you take it in a certain dose according to the instructions ${ }^{[1-2]}$, but it will cause harm to human health when the prescribed dose is exceeded, it may cause liver damage, acute liver failure, coma and even death ${ }^{[3]}$. As an important neurotransmitter of hormones and phenolamines, Dopamine (DA) is widely in the body fluid and brain tissue of mammals and plays an important role in the nervous system and have various physiological functions ${ }^{[4,5]}$. The content of DA in normal humans is within $0.01-10 \mu \mathrm{M}$. The abnormal concentration changes of DA usually cause a variety of diseases, for example, very low concentrations of DA will cause Epilepsy, Parkinson, and Dementia ${ }^{[6,7]}$ while the content of Dopamineat at high level will affect sympathy Nerves and then increases heart rate and blood pressure ${ }^{[8]}$. Therefore, the rapid, sensitive and accurate detection of AMP and DA plays a decisive role in the diagnosis and clinical treatment of related diseases. Currently, there are many methods used for the detection of AMP and DA, among which the electrochemical method has 
attracted people's attention because of its simple production, rapid response, high sensitivity and low cost. Therefore, it is very important to research and develop new electrochemical sensors with sensitive response and stable performance for the determination of AMP and DA.

The materials that used in the preparation of electrochemical sensors are particularly important. Appropriate modified materials can effectively improve the sensitivity and selectivity of the sensors. The materials we often use are gold nanoparticles, metal compound materials and carbon materials, Among them, it is the gold nanoparticles (AuNPs)that most widely used in electrochemical sensors for its unique physical and chemical properties (non-toxicity, high conductivity, high catalytic activity, large specific surface area, excellent Biocompatibility and long-term stability $)^{[9,10]}$. Metal oxide nanoparticles have good optical properties, mechanical properties and excellent catalytic activity ${ }^{[11]}$. The nanoparticles have obvious catalytic effects because of the small size and large specific surface area. $\mathrm{MoO}_{2}$ nanoparticles can be used for electrochemical sensing for its good metallic and conductive properties, high electron transfer rate. In addition, the pore structure in the crystal lattice facilitates the inflow and outflow of charged particles ${ }^{[12]}$, Graphene has hydrogen storage characteristics, field effect characteristics, high strength characteristics, extraordinary specific surface area, high electrical conductivity and fast electron transfer ability ${ }^{[13,14]}$, which are known as the best material at room temperature at present, the speed of electron movement in it far superior to that of that ordinary conductors ${ }^{[15]}$. In addition, Graphene also shows very good adsorption performance of aromatic organic matter ${ }^{[16]}$, which effectively enrich the analyte to improve the sensitivity of the sensor. But nanoparticles are easy to agglomerate so that their properties are affected, So we used Graphene as an ideal substrate for supporting $\mathrm{MoO}_{2}$ electrode active materials, $\mathrm{MoO}_{2}$ nanoparticles were dispersed on Grapheme. The result shows better dispersibility, smaller particle size and higher catalytic activity.

Based on the above analysis, the $\mathrm{Au}$ NPS / $\mathrm{RGO}-\mathrm{MoO}_{2} / \mathrm{GCE}$ electrochemical sensor was prepared by using the drip coating method and electrodeposition method. The sensor can realize the simultaneous detection of acetaminophen and dopamine, and it has high electrocatalytic capacity and good electrical conductivity to separate the two well. The method is sensitive and reliable and also has practical value.

\section{Experimental part}

\subsection{Experimental reagents and experimental instruments}

Uric acid (Shanghai Chemical Reagent Company); Dopamine (Shanghai Zhong qin Chemical Reagent Co., Ltd.); Ammonium Molybdate (Hubei Jusheng Technology Co., Ltd.); Sodium Dihydrogen Phosphate (Jiangsu Caiwei Biological Technology Co., Ltd.); Disodium hydrogen phosphate ( Jiangsu Caiwei Biological Technology Co., Ltd.); concentrated sulfuric acid (Tianjin Damao Chemical Reagent Factory); Potassium ferricyanide (China Xuzhou Reagent Factory); hydrazine hydrate (Shanghai Science and Technology Co., Ltd.); potassium ferrocyanide (Xuzhou Reagent, China) General Plant); Graphite Powder (Tianjin Fuchen Chemical Reagent Factory); Chloroauric acid, analytical reagent, product of Shanghai Aladdin Biochemical Technology Co., Ltd. 
Muffle furnace (Hefei Kejing Material Technology Co., Ltd.); Drying box (Shanghai Heng Scientific Instrument Co., Ltd.); Ultrasonic instrument (Kunshan Ultrasonic Instrument $\mathrm{Co}$, Ltd.); $\mathrm{pH}$ meter (OHRUS) Koster Electrochemical Workstation(Deshang Technology Company); Three-electrode system (Pt electrode is the counter electrode, saturated calomel electrode is the reference electrode, and the glassy carbon electrode modified with $\mathrm{MoO}_{2} / \mathrm{RGO}$ is the working electrode)

\subsection{Molybdenum dioxide nanoparticles-Graphene preparation process}

We heated $1.5 \mathrm{~g}$ of $\left(\mathrm{NH}_{4}\right)_{6} \mathrm{Mo}_{7} \mathrm{O}_{24}$ up to $500^{\circ} \mathrm{C}$ in an argon atmosphere and control the gas flow rate to $0 \mathrm{sccm}$, the temperature was increased at a rate of $10^{\circ} \mathrm{C} / \mathrm{min}$. After keeping it for 2 hours, it was naturally cooled and washed with water, and dried at $60^{\circ} \mathrm{C}$ for 12 hours and then we got $\mathrm{MoO}_{2}{ }^{[17]}$. Graphene oxide was obtained according to the literature ${ }^{[18]}$, We added $1.0 \mathrm{~g} \mathrm{MoO}_{2}$ and a certain amount of GO powder to $50 \mathrm{~mL}$ ultrapure water and stirred continuously then wash it with ultrapure water, and place the sediment in a vacuum drying oven at $60^{\circ} \mathrm{C}$. Then we put the composite material into a tube furnace under nitrogen atmosphere to control its flow rate and heated at $5^{\circ} \mathrm{C} / \mathrm{min}$ to $500^{\circ} \mathrm{C}$ for $2 \mathrm{~h}$ to obtain a black powder sample.

\subsection{Pretreatment of glassy carbon electrode and preparation of Au NPs / RGO- $\mathrm{MoO}_{2}$ / GCE modified electrode}

The pretreatment of the glassy carbon electrode: Polish the glassy carbon electrode with $\mathrm{Al}_{2} \mathrm{O}_{3}$ suspension into a mirror surface, wash it ultrasonically with ethanol and water, and dry it with nitrogen for use. Then we pipetted 5.0 $\mathrm{uL}$ of $\mathrm{RGO}-\mathrm{MoO}_{2}$ and then dispersed it onto the surface of the glassy carbon electrode and dried it naturally to obtain RGO- $\mathrm{MoO}_{2} / \mathrm{GCE}$ modified electrode. The modified electrode was placed in a $0.1 \mathrm{~g} / \mathrm{L} \mathrm{HAuCl} 4$ solution and deposited for $80 \mathrm{~s}$ at a constant potential of $-0.2 \mathrm{~V}$ to obtain $\mathrm{AuNPs} / \mathrm{RGO}-\mathrm{MoO}_{2} / \mathrm{GCE}$.

\section{Results and discussion}

\subsection{Characterization of electrode materials}

It can be seen from Figure 1(A) that $\mathrm{MoO}_{2}$ presents an irregular aggregated granular structure. We can see from figure (B) that Graphene has a sheet-layer fold-like structure, which makes graphene have a large specific surface area, and $\mathrm{MoO}_{2}$ particles are well scattered on Graphene without obvious accumulation. From the scanning electron micrograph of Figure 1 (C) We can see that AuNPs showing a dispersed spherical structure and the distribution of gold nanoparticles is also well-distributed. It can be clearly seen from the EDS diagram shown in Figure 1(D)that the composite material is composed of four elements: $\mathrm{C}, \mathrm{O}$, Mo and $\mathrm{Au}$, indicating that the gold nanoparticles were successfully electrodeposited on the RGO- $\mathrm{MoO}_{2} / \mathrm{GCE}$ modification On the electrode, AuNPs/RGO- $\mathrm{MoO}_{2}$ composite material was successfully synthesized. 


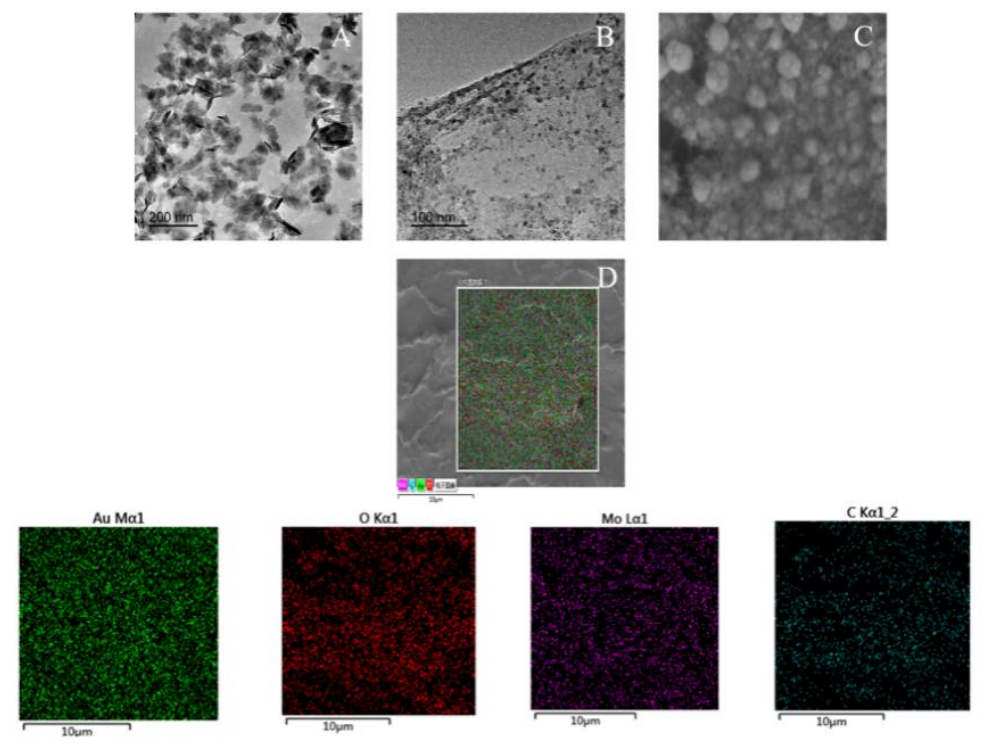

Figure 1 Scanning electron micrograph

It can be observed from the Raman spectrum in Figure 2 that the vibration peak at $230364454494737 \mathrm{~cm}^{-1}$ is the peak of molybdenum dioxide monoclinic crystal. At the same time, it is the two characteristics of graphene D band and $\mathrm{G}$ band at $1349 \mathrm{~cm}^{-}$ ${ }^{1}$ and $1591 \mathrm{~cm}^{-1}$ Peak, when the Graphene oxide was restored and then the D peak in the Raman spectrum was enhanced. The result shows that the two materials are successfully combined.

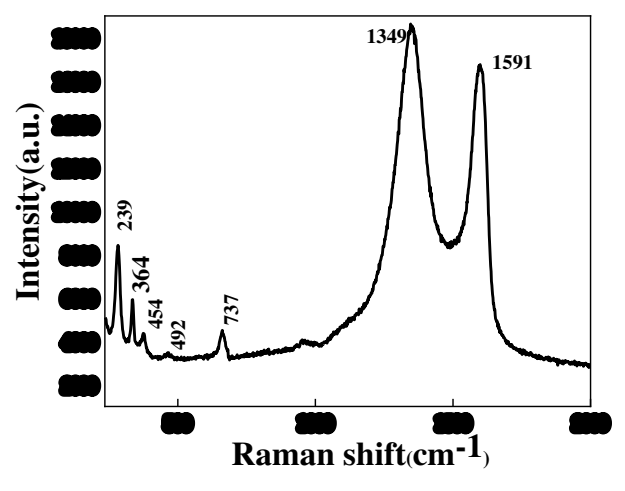

Fig 2. Raman spectra of RGO- $\mathrm{MoO}_{2}$

Figure 3 shows the XPS full spectrum of RGO- $\mathrm{MoO}_{2}(\mathrm{~A})$ high-resolution scans of Mo $3 \mathrm{~d}$ and $\mathrm{C} 1 \mathrm{~s}$ (Figure $\mathrm{B}$ and $\mathrm{C}$ ), and Figure (A) shows that Mo appears in the composite material at the corresponding electronic binding energy. The obvious characteristic peaks of $3 \mathrm{~d}, \mathrm{C} 1 \mathrm{~s}$, Mo $3 \mathrm{p}$ and $\mathrm{O} 1 \mathrm{~s}$ indicates that the existence of three elements. Figure (B) shows the $\mathrm{C}$ element at $1 \mathrm{~s}$ high-resolution spectrum. The fitting peaks at 284.4, 284.6, 286.4, 288.7eV correspond to four different functional groups of carbon atoms: $\mathrm{C}-\mathrm{C} / \mathrm{C}=\mathrm{C}, \mathrm{C}-\mathrm{O}, \mathrm{C}=\mathrm{O}, \mathrm{O}-\mathrm{C}=\mathrm{O}$. The $\mathrm{Mo} 3 \mathrm{~d}$ photoelectron peak in Figure (C) shows that the four components belong to $\mathrm{Mo}^{4+} 3 \mathrm{~d}_{5 / 2}, \mathrm{Mo}^{4+} 3 \mathrm{~d}_{3 / 2}, \mathrm{Mo}^{6+} 3 \mathrm{~d}_{5 / 2}$, $\mathrm{Mo}^{6+} 3 \mathrm{~d}_{3 / 2}$, indicating that $\mathrm{Mo}^{4+}$ was oxidized in the air . Figure (D) shows the XRD of the diffraction peaks on the curve correspond to the monoclinic molybdenum dioxide 
(110) (020) (111) (112) (220) (222) (031) (-231) crystal planes. The characteristic peak intensity on the curve is higher, which proves that it has better crystallinity. The strong molybdenum dioxide (110) diffraction peak masks the graphene diffraction peak (002) at the same angle, so there is no obvious graphene characteristic peak on the XRD curve of the RGO- $\mathrm{MoO}_{2}$ composite material, At the same time, (111) (200) and (220) crystal planes of gold nanoparticles appeared on $\mathrm{Au} \mathrm{NPs} / \mathrm{RGO}-\mathrm{MoO}_{2}$ composites. The above results indicate that the composite material was successfully synthesized.
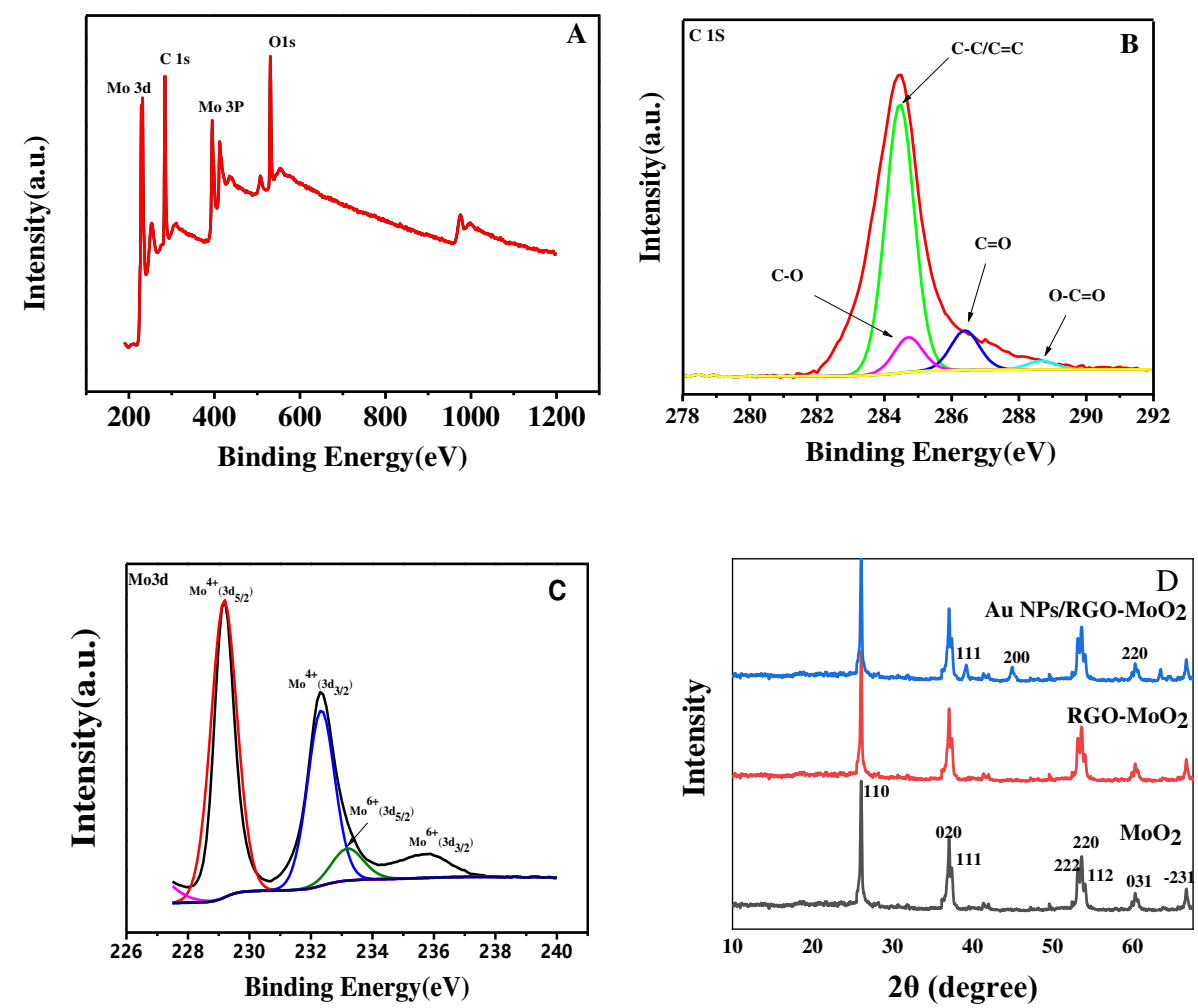

Figure 3 XPS full spectrum of RGO-MoO $2(A)$, high-resolution element scanning images (B,

C) of C1s and Mo3d, and XRD images (D) of Au NPS/RGo-MoO 2

\subsection{Electrochemical properties of Au NPs/RGO-MoO2/GCE}

Figure 4(A) shows that the cyclic voltammetry (CV) graph of different modified electrodes in $0.1 \mathrm{mmol} / \mathrm{L}$ potassium ferricyanide solution. It can be seen from the graph that a pair of broad redox peaks appear on bare GCE(a)and the current is also small. The redox peak was significantly narrowed and the peak current increased significantly when different nanomaterials were modified on the bare GCE. The modified electrode $\mathrm{Au} \mathrm{NPs} / \mathrm{RGO}-\mathrm{MoO}_{2} / \mathrm{GCE}(\mathrm{d})$ had the largest peak current, it was 3 times than that of the bare electrode. This may be due to the higher conductivity of RGO- $\mathrm{MoO}_{2}$ composites and the excellent catalytic activity of AuNPs, which accelerates the electron transfer rate on the electrode surface.

AC impedance (EIS) spectrum in Figure 4 (B) shows that the semicircle d iameter of bare $\operatorname{GCE}(\mathrm{a})$ is the largestin the high frequency region, indicating th e largest resistance. The smallest semicircle diameter of AuNPs/RGO- $\mathrm{MoO}_{2} / \mathrm{GC}$ $\mathrm{E}(\mathrm{d})$ is approximately straight line, which indicates the modified electrode has $\mathrm{t}$ 
he best conductivity, this is consistent with the conclusion drawn from the $\mathrm{CV}$ diagram.
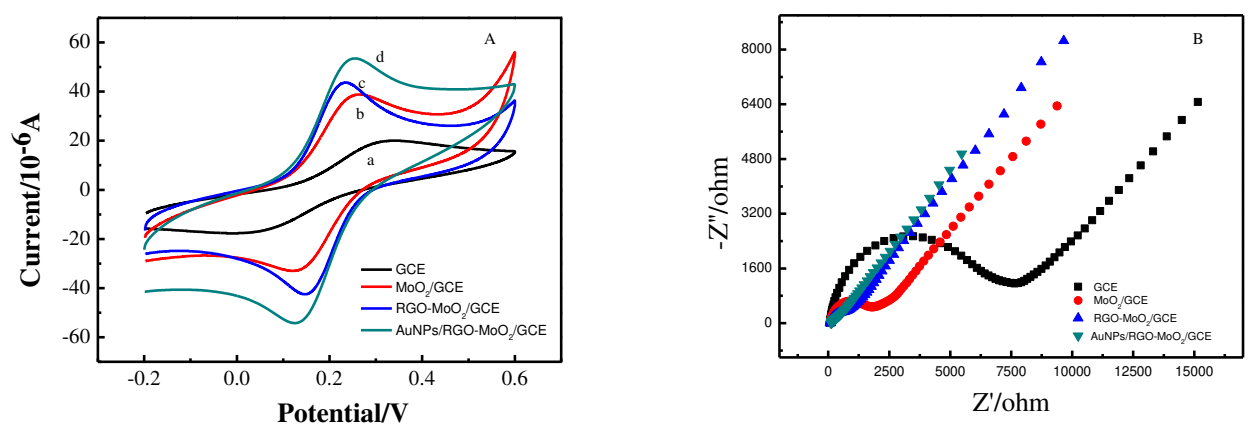

Fig. 4 CV(A) and EIS(B) of bare GCE(a), $\mathrm{MoO}_{2} / \mathrm{GCE}$ (b), RGO-MoO2/GCE (c) and AuNPs /RGO-MoO2/GCE (d)in $0.1 \mathrm{mmol} / \mathrm{L} \mathrm{K} 3[\mathrm{Fe}(\mathrm{CN}) 6]$ containing $0.1 \mathrm{~mol} / \mathrm{L} \mathrm{KCl}$

\subsection{Electrochemical behavior of AMP and DA on different modified electrodes}

The cyclic voltammetry (CV) method was used to investigate the electroch emical behavior of AMP, DA and their mixtures on different electrodes. Figure 5(A) is the CV diagram of different modified electrodes in the PBS solution c ontaining 1mmol/L AMP. An irreversible weak oxidation peak appears on bare $\mathrm{GCE}(\mathrm{a})$. The oxidation peak current of modified $\mathrm{MoO}_{2}$ is higher than that of $\mathrm{t}$ he bare electrode, but the peak is still very weak. When the RGO is continuo usly modified, the oxidation peak is significantly enhanced, indicating that the RGO- $\mathrm{MoO}_{2}$ composite has good conductivity and can makes the current respon se more sensitive. After AuNPs were deposited on $\mathrm{RGO}-\mathrm{MoO}_{2} / \mathrm{GCE}$ electrode, a pair of reversible redox peaks appeared, At the same time, the peak current is greatly enhanced. This might be due to the excellent conductivity and electr ocatalytic properties of $\mathrm{Au} \mathrm{NPs}$, which can accelerate the electron transfer rate on the electrode surface. Figure5(B) is the electrochemical response of 1mmol/ L DA on different modified electrodes. DA has a reversible redox peak on eac $\mathrm{h}$ modified electrode. The peak currents on $\mathrm{GCE}$ and $\mathrm{MoO}_{2} / \mathrm{GCE}$ electrodes we re the weakest while the reversible peak current of DA on $\mathrm{Au}$ NPs/RGO- $\mathrm{MoO}_{2}$ /GCE increases and it is significantly higher than that of $\mathrm{RGO}-\mathrm{MoO}_{2} / \mathrm{GCE}$. Th e reduction peak potential is also significantly positive and the oxidation peak is negative, indicating that $\mathrm{Au} \mathrm{NPs} / \mathrm{RGO}-\mathrm{MoO}_{2} / \mathrm{GCE}$ composite material has str ong electrocatalytic activity. Figure $5(\mathrm{C})$ is the $\mathrm{CV}$ response of AMP and DA mixed solution on each electrode. It can be seen from the figure that on GCE, $\mathrm{MoO}_{2} / \mathrm{GCE}$ and $\mathrm{RGO}-\mathrm{MoO}_{2} / \mathrm{GCE}$, DA has a pair of redox peaks while AMP has only one anode peak. It can also be seen that with the further modificatio $\mathrm{n}$ of the electrode material, the current response signals of AMP and DA incre ase in turn, and the redox peaks of the two are clearly separated, indicating th at AuNPs/RGO- $\mathrm{MoO}_{2} / \mathrm{GCE}$ has a catalytic effect on both AMP and DA. It can be used for simultaneous determination of AMP and DA. 

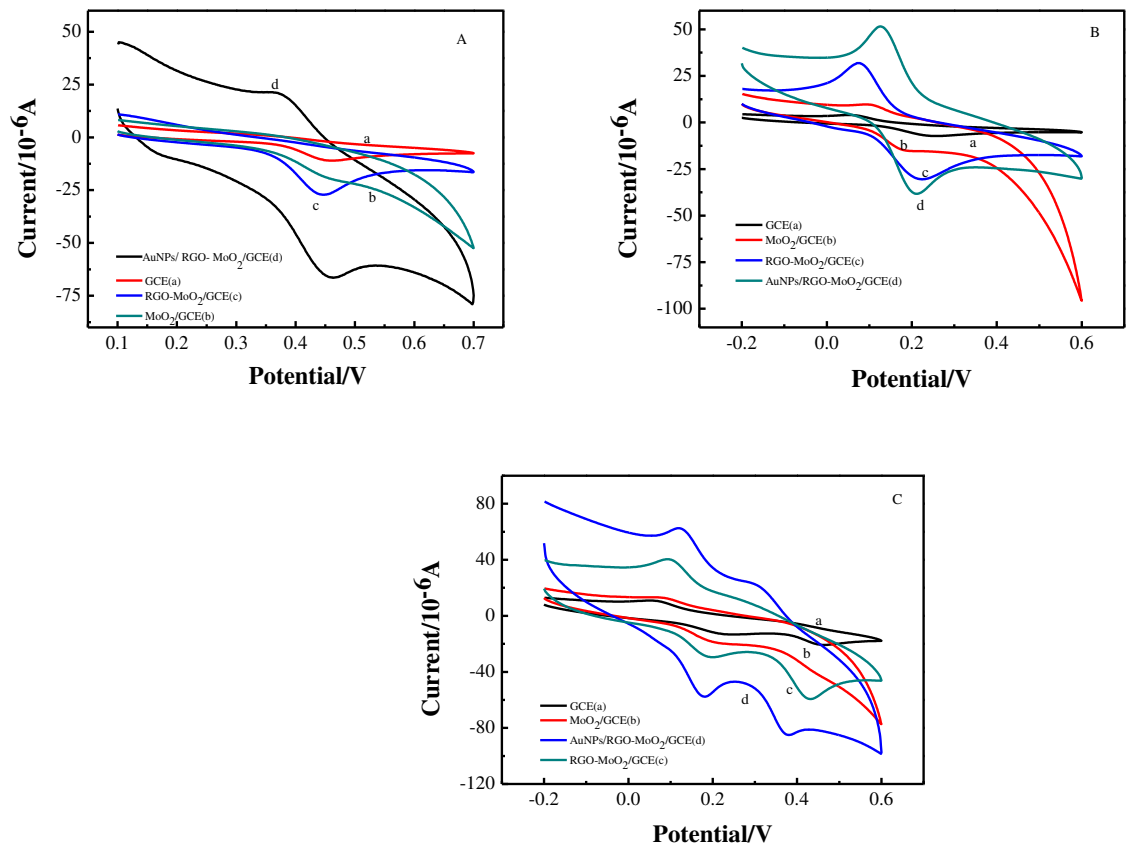

Fig.5 CVs of $1 \mathrm{mmol} / \mathrm{L}$ AMP(A), $1 \mathrm{mmol} / \mathrm{L} \mathrm{DA}(\mathrm{B})$ and the mixture solution of $1 \mathrm{mmol} / \mathrm{L} \mathrm{AMP}$ and $1 \mathrm{mmol} / \mathrm{L}$ $\mathrm{DA}(\mathrm{C})$ in (pH=6.0, PBS) solution on GCE(a), MoO2/GCE (b), RGO- $\mathrm{MoO}_{2} / \mathrm{GCE}$ (c) and AuNPs/RGO-

$\mathrm{MoO}_{2} / \mathrm{GCE}(\mathrm{d})$, respectively

\subsection{The influence of buffer solution $\mathrm{pH}$}

In order to improve the electrochemical sensing performance of the modified electrode, the influence of $\mathrm{pH}$ value $(5.0,5.5,6.0,6.5,7.0)$ on the electrochemical behavior of AMP and DA on AuNPs/RGO- $\mathrm{MoO}_{2} / \mathrm{GCE}$ electrode was studied by DPV method. As shown in Figure 6 (A), the anode peak current values of AMP and DA increase with the increase of $\mathrm{pH}$ value. When the $\mathrm{pH}$ value is 6.0 , the peak currents of $\mathrm{AMP}$ and DA both reach the maximum. When the $\mathrm{pH}$ value is increased continuously, then the peak current of AMP and DA decreases, so we choose $\mathrm{pH}=6.0$ as the best value. Figure 6(B) shows that the oxidation peak potentials of AMP and DA move to a lower potential with the increase of $\mathrm{pH}$, indicating that protons participated in the electrochemical oxidation process of AMP and DA, and their peak potentials have a linear relationship with $\mathrm{pH}$. The linear regression equation is AMP: $\mathrm{Epa}(\mathrm{V})=-$ $0.0338 \mathrm{pH}+0.5961(\mathrm{R} 2=0.9938), \mathrm{DA}: \mathrm{Epa}(\mathrm{V})=-0.0459 \mathrm{pH}+0.4556(\mathrm{R} 2=0.9949)$. The absolute value of the slope is close to the theoretical value of $59 \mathrm{mV} / \mathrm{pH}$, indicating that the number of protons and electrons involved in the electrochemical reaction of AMP and DA are equal ${ }^{[20]}$. 

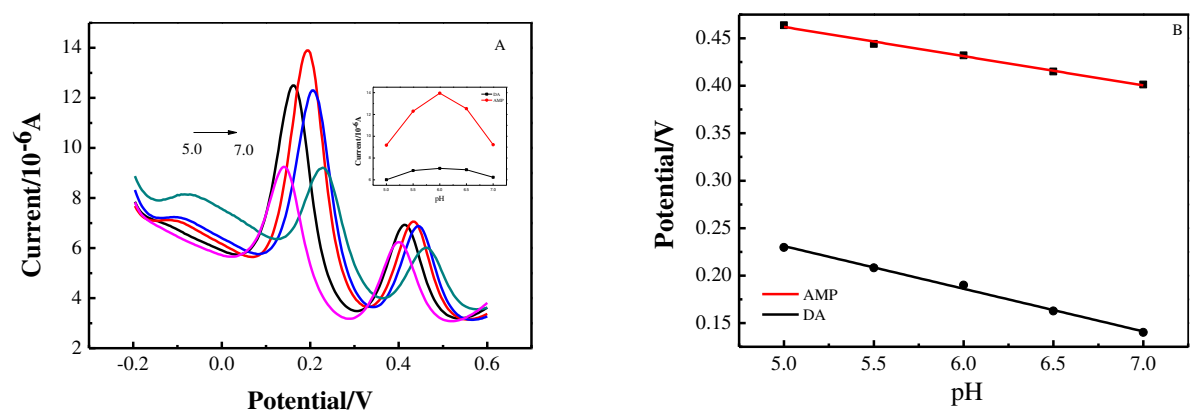

Fig. 6 (A) Effects of the $\mathrm{pH}$ on the oxidation peak current(A) and potential(B) of AMP and AP

\subsection{Influence of scan rate}

In order to explore the kinetics of the oxidation process of AMP and DA on the AuNPs/RGO- $\mathrm{MoO}_{2} / \mathrm{GCE}$ electrode surface, the influence of the scan rate on the peak current was further studied by CV method. Figure 7 (A,B) shows that in the PBS solution containing $0.1 \mathrm{mmol}$ AMP and $0.2 \mathrm{mmol} \mathrm{DA}$ respectively, the redox peak currents of AMP and DA increase with the increase of scanning speed, and the oxidation peak potential is more positive, and the reduction peak potential is more negative, indicating that the redox process of AMP and DA on the electrode is reversible. In addition, the linear relationship between peak current and sweep speed is shown in the inset figure. The linear regression equations of AMP and DA are: I pa $(\mu \mathrm{A})=-16.1632$ $0.2146 \mathrm{v}(\mathrm{mV} / \mathrm{s})\left(\mathrm{R}^{2}=0.9978\right), \operatorname{Ipc}(\mu \mathrm{A})=6.2517+0.1427 v(\mathrm{mV} / \mathrm{s})\left(\mathrm{R}^{2}=0.9957\right)$ and $\operatorname{Ipa}(\mu \mathrm{A})=-26.1992-0.8779 \mathrm{v}(\mathrm{mV} / \mathrm{s})\left(\mathrm{R}^{2}=0.9962\right), \operatorname{Ipc}(\mu \mathrm{A})=13.5146+0.8397 v(\mathrm{mV}$ $/ \mathrm{s})\left(\mathrm{R}^{2}=0.9950\right)$, indicating that the redox reaction of AMP and DA on AuNPs/RGO$\mathrm{MoO}_{2} / \mathrm{GCE}$ is an adsorption control process.
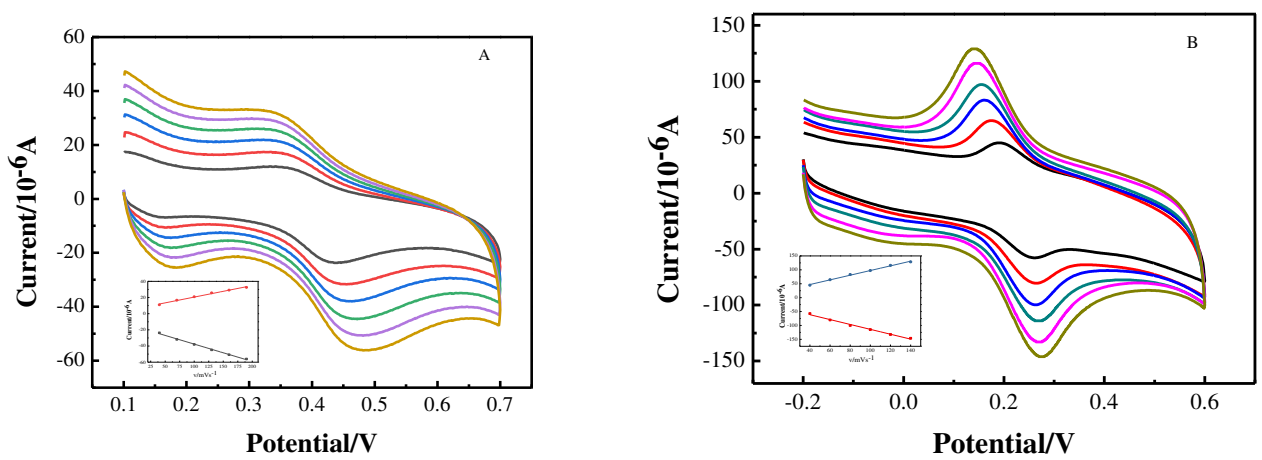

Fig. 7 Cyclic voltammograms of AMP(A) and DA(B) on AuNPs/RGO-MoO $/$ GCE at the different scan rates in 0.1 $\mathrm{mol} / \mathrm{L}$ PBS ( $\mathrm{pH}=7.0)$, Inset: Plot of peak current vs.

The relationship between peak potential and sweep speed is shown in Figure 8 (A, B). It can be seen that the peak potential of AMP and DA has a linear relationship with the natural logarithm (lnv) of the sweep speed. The linear regression equation of AMP is $\mathrm{Epa}(\mathrm{V})=0.3447+0.02475 \operatorname{lnv}(\mathrm{mV} / \mathrm{s})(\mathrm{R} 2=0.9967)$; Epc $(\mathrm{V})=0.4592-0.0255 \operatorname{lnv}$ $(\mathrm{mV} / \mathrm{s})\left(\mathrm{R}^{2}=0.9973\right)$; the linear regression equation of $\mathrm{DA}$ is $\mathrm{Epa}(\mathrm{V})=0.1800+$ $0.0199 \operatorname{lnv}(\mathrm{mV} / \mathrm{s})(\mathrm{R} 2=0.9967) ; \operatorname{Epc}(\mathrm{V})=0.3004-0.0296 \operatorname{lnv}(\mathrm{mV} / \mathrm{s})\left(\mathrm{R}^{2}=0.9973\right)$. According to Laviron theory ${ }^{[21]}$, the electron transfer numbers of AMP and DA were 
calculated to be 1.79 and 2.34 respectively.
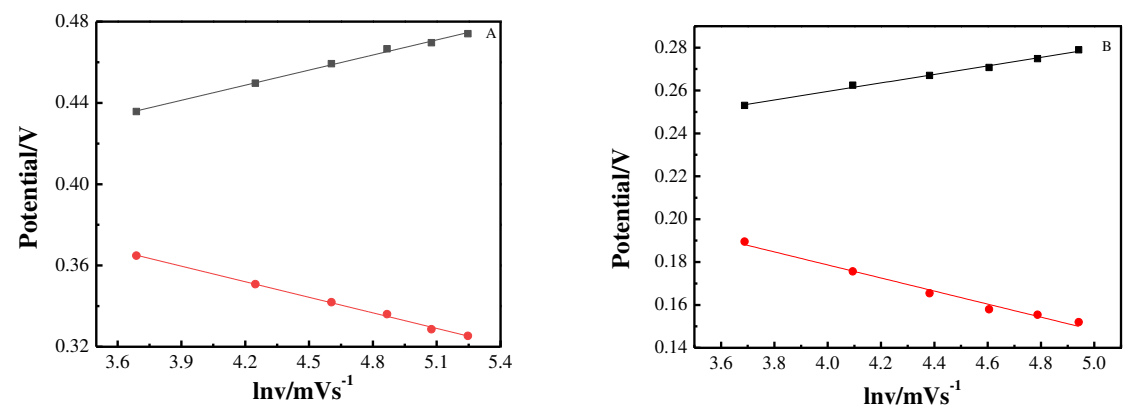

Fig. 8 Relationships between the peak potentials and natural logarithm of the potential scanning rates for AMP(A) and DA(B)

According to the results that obtained, the reaction of AMP and DA on the modifi ed electrode is a 2-proton process, and the possible reaction mechanism is speculate $\mathrm{d}$ as shown in the figure below.<smiles>CC(=O)Nc1ccc(O)cc1</smiles><smiles>NCCC1=CCC(=O)C(=O)C1</smiles>

Fig. 9 Response mechanism of AMP and DA on the modified electrodes

\subsection{Simultaneous determination of AMP and DA}

The relationship between the electrochemical response current of AMP and DA on AuNPs/RGO- $\mathrm{MoO}_{2} / \mathrm{GCE}$ and their concentration in PBS $(\mathrm{pH}=6.0)$ solution were studied by DPV method. As shown in Figure 10(A), when the fixed concentration of $\mathrm{DA}$ is $30 \mu \mathrm{mol} / \mathrm{L}$ and the concentration of AMP varied in the range of $0.05 \sim 320 \mu \mathrm{mol} / \mathrm{L}$, the oxidation peak current has a good linear relationship with the concentration. The linear regression equation is $\operatorname{Ip}(\mu \mathrm{A})=-0.0706 \mathrm{c}(\mu \mathrm{mol} / \mathrm{L})-6.5156\left(\mathrm{R}^{2}=0.9957\right)$, the detection limit is $7.2 \mathrm{nmol} / \mathrm{L}(\mathrm{S} / \mathrm{N}=3)$. Figure $10(\mathrm{~B})$ shows that when the fixed concentration of AMP is $30 \mu \mathrm{mol} / \mathrm{L}$ and the concentration of DA changes within the range of $0.6 \sim 260 \mu \mathrm{mol} / \mathrm{L}$, the oxidation peak current has a good linear relationship with the concentration. The linear regression equation is $\operatorname{Ip}(\mu \mathrm{A})=-0.1387 \mathrm{c}(\mu \mathrm{mol} / \mathrm{L})-$ $11.6271(\mathrm{R} 2=0.9974)$, the detection limit is $13 \mathrm{nmol} / \mathrm{L}(\mathrm{S} / \mathrm{N}=3)$. It shows that the modified electrode has high sensitivity. 

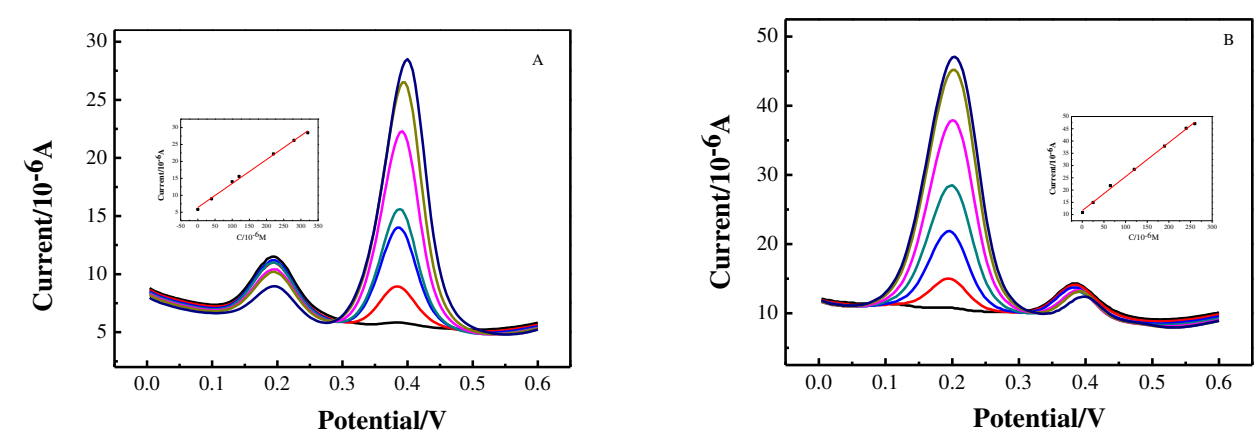

Fig. 10 DPVs of different concentrations of AMP solutions containing $30.0 \mu \mathrm{mol} / \mathrm{L} \mathrm{DA}(\mathrm{A})$ and different concentrations of DA solutions containing $30.0 \mu \mathrm{mol} / \mathrm{L}$ AMP(B) on AuNPs/RGO-MoO2/GCE modified electrode.

Inset: Calibration plots of the anodic peak current versus concentrations of AMP and DA

In order to further verify the ability of AuNPs/RGO-MoO $/ \mathrm{GCE}$ to simulta neously detect AMP and DA, the concentrations of AMP and DA were change $\mathrm{d}$ together to test the DPV response of the mixed solution. The results are sho wn in Figure 11(A). As the concentrations of AMP and DA increase, the oxid ation peak currents of the two increase correspondingly at the same time. The peak current and concentration are in a linear relationship, and the peak shapes are completely separated and not interferedwith each other. The corresponding linear equations are $\mathrm{Ip}(\mu \mathrm{A})=-0.0598 \mathrm{c}(\mu \mathrm{mol} / \mathrm{L})-9.2232\left(\mathrm{R}^{2}=0.9985\right)$ and $\mathrm{Ip}(\mu$ $\mathrm{A})=-0.0765 \mathrm{c}(\mu \mathrm{mol} / \mathrm{L})-10.7175\left(\mathrm{R}^{2}=0.9949\right)$. The concentration ranges of $\mathrm{A}$ MP and DA are $0.09 \sim 250 \mu \mathrm{mol} / \mathrm{L}$ and $0.4 \sim 250 \mu \mathrm{mol} / \mathrm{L}$, respectively. Compared $\mathrm{w}$ ith the reported sensors, AuNPs/RGO- $\mathrm{MoO}_{2} / \mathrm{GCE}$ has a lower detection limit a nd a wider linear range, which can be appliedm in the Simultaneous detection of AMP and DA (Table 1).
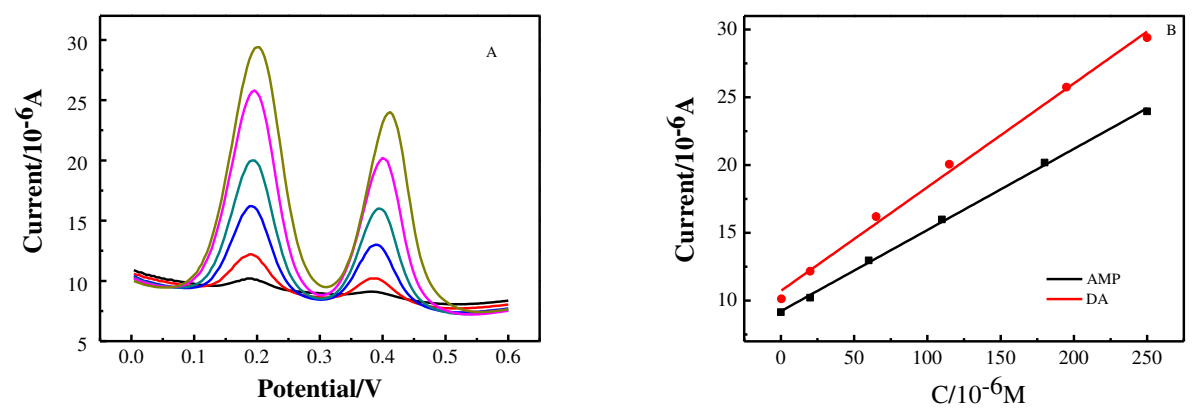

Fig. $11 \mathrm{DPVs}$ of different concentrations of $\operatorname{AMP}(0.09,20,60,110,180,250 \mu \mathrm{mol} / \mathrm{L})$ and $\mathrm{DA}(0.4,20,65,115$, $195,250 \mu \mathrm{mol} / \mathrm{L}$ ) on AuNPs/RGO- $\mathrm{MoO}_{2} / \mathrm{GCE}$ modified electrode in $0.1 \mathrm{~mol} \cdot / \mathrm{L}$ PBS ( $\mathrm{pH}=7.0$ ) (A) and calibration plots of the anodic peak current versus concentration of AMP and AP(B)

Table 1 Comparison of the analyticle performance of the different modified electrodes for determining AMP and DA

\begin{tabular}{cccccc}
\hline Electrode & \multicolumn{2}{c}{ Linear range $(\mu \mathrm{mol} / \mathrm{L})$} & \multicolumn{2}{c}{ Detection limit $(\mu \mathrm{mol} / \mathrm{L})$} & \multicolumn{2}{c}{ Refs. } \\
& AMP & DA & AMP & DA & \\
\hline NiO-CuO/GR/GCE & $4-400$ & $0.5-20$ & 1.33 & 0.17 & 22
\end{tabular}




\begin{tabular}{cccccc} 
TCPP-Sa/CPE & $1-90$ & $0.4-10.3$ & 0.2 & 0.1 & 23 \\
AG-NAmodified/GCE & $0.1-8$ & $1-26$ & 0.031 & 0.33 & 24 \\
3D-MoS $/$ rGO/Au/GCE & - & $0.3-198.3$ & - & 0.15 & 25 \\
$\mathrm{RGO}_{\mathrm{M} \mathrm{MOO}_{2} / \mathrm{AuNP} / \mathrm{GCE}}$ & $0.05-320$ & $0.6-260$ & 0.0072 & 0.013 & This work \\
\hline
\end{tabular}

\subsection{Anti-interference ability, repeatability and stability of AMP and DA sensors}

The anti-interference ability of AuNPs/RGO-MoO $/$ GCE electrode was tested by adding some coexisting substances in the PBS solution of AMP and DA. As shown in Figure 12, amount to 100 times the concentration of inorganic ions such as $\mathrm{Ca}^{2+}, \mathrm{Cu}^{2+}$, $\mathrm{Na}^{+}, \mathrm{Cl}^{-}, \mathrm{NO}^{2-}$ and amount to 50 times the concentration of glucose, caffeine, salicylic acid, etc,they all have no significant interference in the determination of AMP and DA. The relative error of DA is less than 5\% and the relative error of AMP is less than $10 \%$, indicating that the modified electrode has good selectivity for AMP and DA.

We prepared four AuNPs/RGO- $\mathrm{MoO}_{2} / \mathrm{GCE}$ electrodes independently with the same method and tested the PBS $(\mathrm{pH}=6)$ solution containing $0.2 \mathrm{mmol} / \mathrm{LAMP}$ and 0.2 $\mathrm{mmol} / \mathrm{LDA}$ to obtain the relative standard deviation (RSD) of AMP and DA are $2.48 \%$ and $2.76 \%$ respectively, it indicates that the modified electrode preparation process has good repeatability. After 50 consecutive cycles of cyclic voltammetry, the oxidation peak response currents of AMP and DA were $90.10 \%$ and $91.80 \%$ of their initial value respectively, this indicates that the modified electrode has good stability.

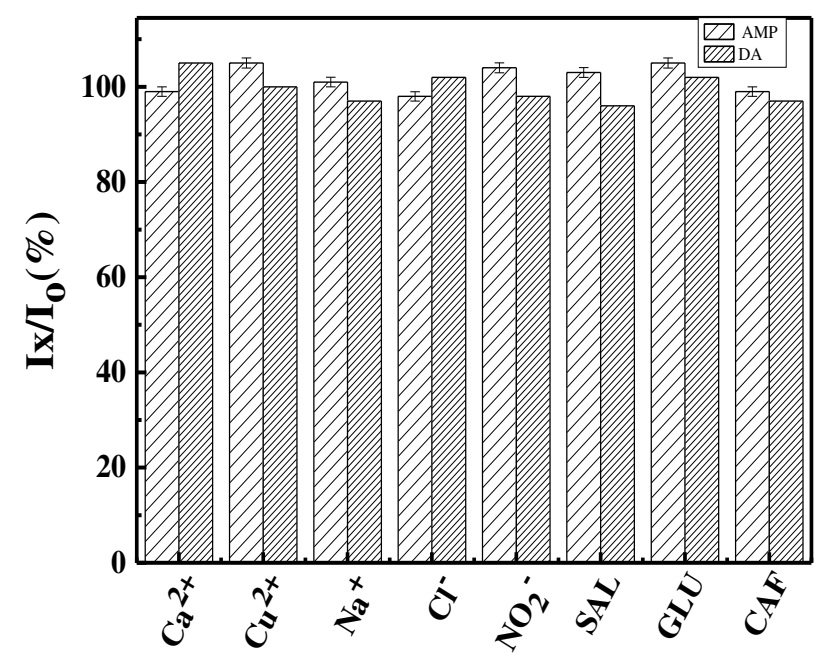

Fig.11 Effects of some organic molecules and inorganic ions on electrochemical determination of AMP and

DA

\subsection{Analysis of actual samples}

In order to evaluate the practicality of $\mathrm{AuNPs} / \mathrm{RGO}-\mathrm{MoO}_{2} / \mathrm{GCE}$, We used the sensor to measure commercially available acetaminophen tablets and human urine samples. After pretreatment of the sample (pills were crushed and dissolved, filtered and diluted, and the urine was centrifuged and then the supernatant was diluted), it is measured by the standard addition method. The results show that the recoveries of the 
two are $95.84 \% \sim 100.60 \%$ and $98.73 \% \sim 103.10 \%$ respectively. The standard deviations of the three parallel determinations were all less than 5\%, indicating that the modified electrode can be used for the detection of actual samples (Table 2).

Table 2 Determination of acetaminophen and dopamine in actual samples $(n=3)$

\begin{tabular}{|c|c|c|c|c|c|c|c|c|c|c|}
\hline \multirow[t]{2}{*}{ Sample } & \multicolumn{2}{|c|}{$\begin{array}{l}\text { Detected } \\
(\mu \mathrm{mol} / \mathrm{L})\end{array}$} & \multicolumn{2}{|c|}{$\begin{array}{c}\text { Add } \\
(\mu \mathrm{mol} / \mathrm{L})\end{array}$} & \multicolumn{2}{|c|}{$\begin{array}{c}\text { Found } \\
(\mu \mathrm{mol} / \mathrm{L})\end{array}$} & \multicolumn{2}{|c|}{$\begin{array}{c}\text { Recovery } \\
(\%)\end{array}$} & \multicolumn{2}{|c|}{ RSD(\%) } \\
\hline & AMP & DA & AMP & DA & AMP & $\mathrm{DA}$ & AMP & DA & AMP & DA \\
\hline 尿液 1 & - & - & 30 & 30 & 30.19 & 29.98 & 100.6 & 99.93 & 2.24 & 2.56 \\
\hline 尿液 2 & - & - & 40 & 60 & 38.95 & 59.25 & 97.38 & 98.75 & 4.12 & 1.78 \\
\hline 尿液 3 & - & - & 60 & 80 & 59.45 & 78.98 & 99.08 & 98.73 & 3.68 & 2.45 \\
\hline 药片 1 & 20 & - & 30 & 30 & 48.83 & 30.03 & 96.10 & 100.10 & 2.75 & 1.26 \\
\hline 药片 2 & 20 & - & 50 & 40 & 67.92 & 41.23 & 95.84 & 103.10 & 4.34 & 4.14 \\
\hline 药片 3 & 20 & - & 60 & 80 & 79.91 & 80.69 & 99.85 & 100.90 & 1.98 & 3.28 \\
\hline
\end{tabular}

\section{Summary}

A new type of AuNPs/RGO-MoO $/$ GCE electrochemical sensor was successfully constructed by using Graphene with large specific surface area, the good conductivity of molybdenum dioxide and the high catalytic activity of Au NPs through simple and rapid drop coating and electrodeposition methods.This sensor has good conductivity and high electrocatalytic ability for AMP and DA, which can realize the simultaneous determination of AMP and DA targets without interfering with each other. The method is sensitive, fast, accurate, and selective, This sensor has good performance with wide linear range and good practical application value.

\section{References}

[1] Kung C W, Lin C Y, Vittal R, et al. Synthesis of cobalt oxide thin films in the presence of various anions and their application for the detection of acetaminophen[J]. Sens. Actuators B, 2013, 182: 429-438

[2] Adhikari B R, Govindhan M, Chen A. Sensitive detection of acetaminophen with graphene-based electrochemical sensor[J]. Electrochim. Acta, 2015, 162: 198-204

[3] Anuar N S, Basirun W J, Ladan M, et al. Fabrication of platinum nitrogen-doped graphene nanocomposite modified electrode for the electrochemical detection of acetaminophen[J]. Sens. Actuators B , 2018, 266:373-383

[4] He Y S, Pan C G, Cao H X, et al. Highly sensitive and selective dual-emission ratiometric fluorescence detection of dopamine based on carbon dots-gold nanoclusters hybrid[J], Sens. Actuators B, 2018, 265:371-377

[5] Zhang C, Ren J J, Zhou J X, et al. Facile fabrication of a 3,4,9,10-perylene tetracarboxylic acid functionalized grapheme-multiwalled carbon nanotube-gold nanoparticle nanocomposite for highly sensitive and selective electrochemical detection of dopamine[J]. Analyst, 2018, 143:3075-3084

[6] Gaskill P J, Miller D R, Gamble-George J, et al. HIV, Tat and dopamine transmission[J]. Neurobiol. Dis., 
2017, 105: 105 51-73

[7] Surmeier D J. Determinants of dopaminergic neuron loss in Parkinson's disease[J]. FEBS, 2018, 285: 3657 3668

[8] Fukuda S M, Shirakawa K, Jiko H, Gotoh M. Carbon nanotube multi-electrode array chips for noninvasive real-time measurement of dopamine, action potentials, and postsynaptic potentials[J]. Biosens. Bioelectron., 2013, 49: 49 270-275

[9] Zhao L Y, Li J G, Chen X L, et al. Highly sensitive electrochemical detection of hydrogen peroxide based on polyethyleneimine-Au nanoparticles-zinc protoporphyrin[J]. J. Electrochem. Soc., 2019, 166: B631-B636

[10] Liu X, Fang C, Yan J L, et al. A sensitive electrochemiluminescent biosensor based on AuNPfunctionalized ITO for a label-free immunoassay of Cpeptide[J]. Bioelectrochemistry, 2018, 123: 211-218

[11] Liu H, Yu X L, Chen H F, Liu Y H. Preparation of porous carbon-manganese dioxide nanocomposite for sensitive determination of cadmium ion[J]. Int. J. Electrochem. Sci., 2017, 12: 9736-9746

[12] Zhou J, Xu N S, Deng S Z, et al Large-area nanowire arrays of molydenum and molybdenum oxides:synthesis and field emission properties[J]. Adv. Mater, 2003, 15: 1835.

[13] Li Jialin, Xie Jiale, Gao Lixia, et al. Au nanoparticles-3D graphene hydrogel nanocomposite to boost synergistically in situ detection sensitivity toward cell-released nitric oxide, [J]. ACS Appl. Mater. Interfaces, 2015, 7(4): 2726-2734.

[14] Novikov S, Lebedeva N, Satrapinski A, et al. A. Lebedevd, Graphene based sensor for environmental monitoring of $\mathrm{NO}_{2}[\mathrm{~J}]$. Sens Actuators B Chemical, 2016, 236(29): 1054-1060.

[15] Zhao Yuan, Huang Weijiu. Research Progress on Preparation and Performance of Graphene and Its Composite[J]. Journal of Chongqing University of Technology(N atural Science ), 2011, 25(7):64-70

赵远, 黄伟九, 石墨烯及其复合材料的制备及性能研究进展 [J]. 重庆理工大学学报 (自然科学), 2011, 25 (7) : 64-70

[16] Xie Huanling, Huang Xiaoxue. Overview of photocatalytic Degradation of VOCs by $\mathrm{TiO}_{2}$ Nanocomposites[J]. Journal Of ShanXIi University Of Science \& Echnology, 2019, 33(4): 88-92.

谢焕玲, 黄小雪. $\mathrm{TiO}_{2}$ 纳米复合材料光催化降解 VOCs 的研究进展 $[\mathrm{J}]$. 重庆理工大学学报 (自然科学), 2019, 33(4): 88-92.

[17] Xu Zhanwei, Wang Tian, Liu Xinyue, et al. Effect of Different Atmosphere on Decomposition Products of Ammonium Heptamolybdate[J]. Journal Of ShanXIi University Of Science \& Echnology,2017, 35(03):53-58.

许占位, 王天, 刘金悦, 等.气氛对钼酸铵分解的影响及产物的电化学性能 [J], 陕西科技大学学 报,2017,35(03): 53-58.

[18] Yang Jinghui, Feng Chenxia, Dai Jian, et al. Compatibiliz-ation of immisciblenylon 6/poly(vinylidene fluoride) blends using graphene oxides [J]. Polymer intermational, 2013, 62(7): 1085-1093.

[19] Kumari L, Ma Y R, Tsai C C, et al. X-ray diffraction and Raman scattering studies on large-area array and nanobranched structure of $1 \mathrm{D} \mathrm{MoO}_{2}$ nanorods[J]. Nanotechnology, 2007, 18(11): 1-7.

[20] Liu Z M, Wang Z L, Cao Y Y, Jing Y F, Liu Y L. High sensitive simultaneous determination

of hydroquinone and catechol basedon graphene/BMIMPF 6 nanocomposite modified electrode [J]. Sens. Actuators B, 2011, 157: 540-546

[21] Laviron E. Adsorption, autoinhibition and autocatalysis in polarography and in linear potential sweep voltammetry [J]. J. Electroanal. Chem. Interfacial Electrochem., 2004, 60: 669-676

[22] Liu B, Ouyang X, Ding Y, et al. Electrochemical preparation of nickel and copper oxides-decorated grapheme composite for simultaneous determination of dopamine acetaminophen and tryptophan[J]. Talanta, 2016, 146:141-121

[23] Kemmegne-Mbouguen J C, Ngameni E. Simultaneous quantification of dopamine, acetaminophen and 
tyrosine at carbon paste electrode modified with porphyrin and clay[J]. Anal. Methods, 2017, 9: 4157-4166.

[24] Kim D, Lee S, Piao Y. Electrochemical determination of dopamine and acetaminophen using activated grapheme-Nafion modified glassy carbon electrode[J]. J. Electroanal. Chem., 2017,794: 221-228.

[25] Zhao Y, Zhou J, Jia Z, et al. In-situ growth of gold nanoparticles on a 3D-network consisting of a MoS $2 / \mathrm{rGO}$ nanocomposite for simultaneous voltammetric determination of ascorbic acid, dopamine and uric acid[J]. Microchim. Acta, 2019, 186: 92 